\title{
El juego dialógico del discurso de Menem con la estructura partidaria del peronismo durante la etapa de sedimentación de la hegemonía neoliberal ${ }^{*}$
}

\author{
Hernán Fair ${ }^{* *}$
}

\section{Resumen}

El presente trabajo analiza el juego dialógico del discurso de Menem con la estructura partidaria del peronismo, colocando el eje en la etapa de sedimentación de la hegemonía menemista. Para ello, asume una perspectiva construccionista de análisis del discurso, examinando el juego de desarticulación y rearticulación de significantes privilegiados y el discurso de legitimación política de las reformas neoliberales.

\section{Palabras clave}

Neoliberalismo - Menemismo - Juego dialógico, Partido Justicialista - Análisis del discurso.

\footnotetext{
*Artículo recibido el 10 de junio de 2013. Aceptado el 30 de julio de 2013.

Este artículo se inscribe en el marco de una investigación más amplia, que constituyó mi Tesis de Doctorado en Ciencias Sociales, marzo de 2013. Agradezco especialmente a Javier Balsa por sus relevantes contribuciones al marco teórico-metodológico del presente trabajo, varios de cuyos ejes son producto de consideraciones de su propia autoría. Además, agradezco los valiosos comentarios y críticas del par evaluador.

** Doctor en Ciencias Sociales por la Universidad de Buenos Aires (UBA). Becario Post-Doctoral del Consejo Nacional de Investigaciones Científicas y Técnicas (CONICET), con sede en la Universidad Nacional de Quilmes (UNQ). Docente de la Carrera de Ciencia Política de la Universidad de Buenos Aires (UBA). Contacto: herfair@hotmail.com / hernanfair@conicet.gov.ar
} 


\section{Abstract}

This paper analyzes the dialogic game from Menem's speech with the Peronist party structure, placing the shaft in the sedimentation stage of menemist hegemony. To do that, takes a constructionist perspective of discourse analysis, examining the disarticulation and re-articulation game of privileged signifiers and the political discourse of legitimation of neoliberal reforms.

\section{Keywords}

Neoliberalism - Menemism - Dialogic play - Justicialist Party - Discourse analysis.

\section{Introducción}

\section{Introducción}

El peronismo, durante la segunda posguerra, construyó un Estado Social que garantizó amplios beneficios sociolaborales para los trabajadores y sectores populares. En el transcurso de los años 90, sin embargo, un dirigente que venía de las entrañas del partido-movimiento, Carlos Menem (1989-1999), terminaría por destruir al Estado Social, aplicando un conjunto de políticas neoliberales que profundizaban un proceso de cambio estructural, iniciado a mediados de los años 70 por la dictadura cívico militar (1976-1983). En ese marco, como ha sido destacado por una pluralidad de autores, la hegemonía del neoliberalismo en la Argentina, durante los años 90, produjo transformaciones y efectos devastadores a nivel económico y social (AAVV, 1993; Isuani, 1996; Lo Vuolo y Barbeito, 1998; Repetto, 1999; Basualdo, 2000; Lo Vuolo, 2001; Beccaria, 2002; Giosa Zuazúa, 2007; Castellani y Gaggero, 2011). También generó importantes transformaciones a nivel político-institucional (Palermo y Novaro, 1996; Palermo, 1999; Levitsky, 2005). Finalmente, diversos estudios analizaron los cambios ideológicos y culturales de la hegemonía menemista (Grassi, 2004; Rinesi y Vommaro, 2007; Bonnet, 2008), que provocaron una serie de transformaciones estructurales en las identidades y tradiciones existentes (Martuccelli y Svampa, 1997). En esas circunstancias, el menemismo logró edificar, tal vez, la única experiencia realmente hegemónica de toda la historia argentina, construyendo, con un importante grado de 
eficacia, un nuevo sentido común en torno a los valores del neoliberalismo modernizador (Fair, 2013).

Aunque se han examinado, dentro de la bibliografía especializada, las características asumidas por el discurso presidencial que hizo posibles estas transformaciones estructurales (Aboy Carlés, 2001; Barros, 2002, 2009; Canelo, 2002, 2011), no hemos hallado estudios que intenten articular los planos lingüístico y extralingüístico del discurso, de manera tal de examinar el juego de dialogismo que se establece entre el discurso verbal menemista, sus prácticas sociales e institucionales y los discursos de otros enunciadores con los cuales interactuaba en el espacio social. El siguiente trabajo se sitúa en esta poco explorada línea de análisis. En ese marco, colocando el eje en el discurso de Carlos Menem, considerado, por su posición institucional y su poder político y simbólico, la figura central del período, se examina el juego dialógico que establece con la estructura partidaria del justicialismo. De manera específica, se analizan las estrategias de legitimación del discurso presidencial en sus interpelaciones dirigidas a los referentes institucionales de tradición peronista, en la etapa de sedimentación de la hegemonía menemista, durante el año 1993, concentrándose en el proceso de desarticulación y rearticulación de las demandas discursivas de los enunciadores clave pertenecientes a la estructura partidaria del justicialismo.

\subsection{Marco teórico-metodológico}

El marco teórico-metodológico toma como referencia las herramientas de la teoría del discurso de Ernesto Laclau y Chantal Mouffe (1987) y los complementos más recientes de Laclau (2005). En ese contexto, se asume una concepción del discurso en un sentido amplio, que incluye tanto los aspectos lingüísticos, como los extralingüísticos. Proponemos definir al primero como discurso en sentido estricto y al segundo como discurso en sentido amplio. Desde la perspectiva posfundacional de Laclau, el discurso representa el elemento que otorga significación y organiza el orden social. Lo social, a su vez, es entendido como una lucha hegemónica por definir el sentido legítimo del orden y fijar parcialmente los significados en torno a ciertos "puntos nodales" (Laclau y Mouffe 1987).

Este enfoque presenta algunos ejes problemáticos. En primer lugar, carece de una operacionalización de sus principales categorías, manteniéndose en un elevado nivel de abstracción (Howarth, 2010; Balsa, 2011). A ello le debemos agregar que suele concentrarse en el aspecto lingüístico, relegando el plano de lo extralingüístico. Además, no explica cómo articular ambos elementos discursivos. Finalmente, no distingue entre capacidades diferenciales para generar interpelaciones, relegando la capacidad agentiva de los sujetos. Sin pretender solucionar aquí estos problemas metodológicos, afirmamos que se pueden distinguir, en primer lugar, diversos planos 
de análisis de la hegemonía (Balsa, 2013; Fair, 2013). En este trabajo colocaremos el eje el plano de la intertextualidad (Fairclough, 2003), que permite una mayor validación empírica. Específicamente, examinaremos lo que ha sido definido como el "juego dialógico" de "desarticulación y rearticulación" de significantes en diferentes "redes" de enunciados (Balsa, 2011, 2013). En ese sentido, partimos de la base de que la estructuración del orden social debe ser entendida en el marco de un "dialogismo" (Bajtín, 1982), en el que los discursos siempre establecen un "juego" de "interacción social" (Volóshinov, 1992) e "interdiscursividad" (Fairclough, 2003; Sigal y Verón, 2003: 19), brindando una "respuesta", ya sea inmediata o "retardada" (Bajtín, 1982). En toda relación dialógica se establece, además, un diálogo con "ciertos enunciados anteriores", a los cuales se responde (Bajtín, 1982: 263), de modo tal que el dialogismo no es solo con los enunciadores en tiempo presente, sino también con enunciadores que se sitúan en un tiempo histórico pasado.

Desde la perspectiva de Bajtín, todo discurso es dialógico. Sin embargo, se pueden pensar diversos grados de dialogismo. En ese sentido, un discurso "monologal" (Bajtín, 1982) es aquel que no toma en cuenta a otros enunciadores y tampoco escucha a los otros, ni atiende a su recepción (Balsa, 2011: 76). Un discurso "dialogista", en cambio, sería aquel que presenta tres características. En primer lugar, que incorpora diferentes textos para construir sus interpelaciones. En segundo término, que escucha y dialoga con otras discursividades y otorga autonomía agentiva a los demás enunciadores. Finalmente, que escucha, recoge e incluye, en diverso grado, las "demandas sociales insatisfechas" (Laclau, 2005) de los agentes a quienes interpela, reformulándolas parcial o totalmente y otorgándoles una determinada significación ${ }^{1}$.

Como un presupuesto adicional, se asume que los sujetos políticos adquieren una relativa autonomía para construir interpelaciones y generar identificaciones, de modo tal que el discurso presenta un papel "activo" y "productivo" (Bajtín, 1982; Volóshinov, 1992; Fairclough, 2003), capaz de reformular las identidades existentes (Laclau y Mouffe, 1987; Aboy Carlés, 2001) y, por lo tanto, de adquirir un papel central en la construcción de la hegemonía (Laguado Duca, 2011: 43). Sin embargo, no todos los agentes presentan igual capacidad de generar articulaciones (Howarth, 2010), lo que implica una capacidad diferencial de construir interpelaciones eficaces. Según sostenemos, solo determinados agentes políticos, ya sea por su posición institucional, su poder político, económico o simbólico (en sentido estricto), u otros elementos vinculados con el estilo enunciativo o a los aspectos identitarios, presentan una eficacia performativa potencial para generar identificaciones y construir con éxito una articulación hegemónica. A partir de esta propuesta, desde la teoría construccionista de Laclau, se puede visualizar el análisis del juego de desarticulación y rearticulación de significantes que se produce entre determinados discursos que generan interpelaciones

\footnotetext{
${ }^{1}$ Esta caracterización surgió de una conversación personal con Javier Balsa.
} 
legítimas, e interactúan entre sí con otros discursos posicionados como interpelados, en determinada coyuntura o proceso social ${ }^{2}$.

Tomando como base el análisis de los discursos del presidente Menem³ ${ }^{3}$ la presente investigación coloca el eje en este juego de desarticulación y rearticulación de los significantes privilegiados o clave, que efectúa el discurso presidencial, en relación con los discursos que asumen los referentes institucionales de la estructura partidaria del Partido Justicialista (PJ). Por significantes clave nos referimos a aquellos que son más replicados en el análisis empírico del discurso, en determinada coyuntura. La elección de los discursos de los referentes institucionales del peronismo nos permitirá observar el complejo juego dialógico que realizó el presidente, desde el plano de la construcción de la hegemonía, frente a los discursos que compartían su posicionamiento dentro de la misma tradición peronista. Debemos recordar, en ese sentido, que el menemismo llevaría a cabo una profunda reformulación de aquella identidad, aunque sin dejar, en ningún momento, de insertarse dentro de ella (Palermo y Novaro, 1996; Canelo, 2002, 2011).

Por último, aunque el eje se ubica en el plano de la textualidad, en esta investigación se incorporan, a su vez, algunos elementos extralingüísticos. Proponemos distinguir analíticamente, en ese sentido, entre los componentes lingüísticos o verbales y los extra-lingüísticos. Ello no implica pensar a lo extraverbal por fuera de su construcción simbólica, sino distinguirlos como planos diferenciales, en tanto no es lo mismo, por ejemplo, pensar, decir, hacer, sentir y desear ${ }^{4}$. En segundo término, sostenemos que este plano de lo extralingüístico debe ser revalorizado desde la teoría del discurso de Laclau, que se concentra en demasía en los aspectos específicamente lingüísticos. Sin embargo, existe una serie de condicionamientos, como las prácticas sociales (desde una movilización hasta una práctica de consumo), institucionales (como puede ser la sanción de una ley), económicos (vinculados con la reproducción material de los sujetos), e incluso otros más subjetivos, como los valores, las tradiciones y las "vivencias" (Volóshinov, 1992) parcialmente sedimentadas, que actúan como condiciones discursivas de posibilidad de los discursos. Articulando ambos planos, podemos hallar una pluralidad de componentes sociohistóricos, económicos, institucionales e identitarios, que, sin dejar de ser construcciones simbólicas, actúan

\footnotetext{
2 Partimos de la base de que los discursos, en los estudios empíricos sobre la hegemonía, pueden ser posicionados en tres planos diferenciales: en el plano de la producción del discurso, cuando presentan una elevada capacidad de generar interpelaciones exitosas, en el plano de la recepción o el "reconocimiento" (Verón, 1995), cuando son posicionados como interpelados, y en el de la eficacia interpelativa, cuando se examina el impacto del discurso interpelador sobre los discursos posicionados como interpelados (Fair, 2013). En este trabajo colocaremos el eje en el plano de la producción, a partir del análisis de los discursos de Menem.

${ }^{3}$ Hemos examinado un amplio corpus de discursos presidenciales, del que aquí solo mencionaremos algunos fragmentos. Para un análisis más detallado, véase Fair (2013).

${ }^{4}$ Así, aunque la droga representa un discurso, no es lo mismo hablar de ella o pensar en ella, que consumirla materialmente.
} 
como condicionantes, en sentido amplio, de la acción de los sujetos y de la construcción de sus identidades. Siguiendo a Giddens (1993), sin asumir por ello sus presupuestos onto-epistemológicos ajenos al posfundacionalismo, podemos decir que estos elementos "restringen" $y$, al mismo tiempo, "habilitan", a los sujetos. De este modo, no permiten una plena autonomía, pero tampoco pueden determinar el comportamiento de los agentes, por lo que no pueden actuar como factores explicativos de sus discursos, en un sentido amplio (Fair, 2013).

Según sostenemos, en un intento de complejizar la teoría del discurso de Laclau, entre el plano lingüístico o textual del discurso y el plano extralingüístico, existe una compleja relación de interacción dialéctica. Sin embargo, a diferencia de otras vertientes de análisis del discurso que han destacado este mismo proceso (Fairclough, 2003), no diferenciamos entre "prácticas discursivas" y "prácticas no discursivas" (Foucault, 2008), ya que toda realidad se construye desde el orden simbólico (Laclau y Mouffe, 1987). A partir de la distinción analítica que hemos propuesto, en este trabajo incluiremos el abordaje de este doble plano extralingüístico-físico-institucionalvalorativo-identitario y lingüístico-verbal, de la hegemonía menemista. En ese marco, examinaremos algunos aspectos de la relación dialéctica que se establece entre el discurso verbal de Menem, los hechos discursivos físicos, los elementos normativoinstitucionales, las prácticas sociales y los condicionamientos institucionales y de tradiciones parcialmente sedimentadas ${ }^{5}$.

Para desarrollar el análisis empírico, se examina un corpus que abarca los discursos oficiales del presidente Menem durante su primer período de gobierno, colocando el eje en los discursos oficiales del año 1993. Se incluye, además, el análisis de los discursos público-mediáticos del presidente, y del conjunto de los referentes institucionales del PJ, en la medida en que sus declaraciones políticas (en sentido amplio) fueron reproducidas en los principales medios de prensa gráfica de circulación nacional (Clarín, La Nación y Página 12), durante el período de pre-emergencia (1988) y, particularmente, en la etapa de sedimentación (1993) de la hegemonía menemista. A partir de allí, en una primera parte, se examinan las condiciones extraverbales de posibilidad de la discursividad menemista. Luego, se coloca el eje en el análisis de las interpelaciones ideológicas del presidente y en el juego de desarticulación y rearticulación de las "demandas sociales insatisfechas" (Laclau, 2005) de los enunciadores políticos clave del PJ a nivel institucional. Finalmente, se incorpora un análisis del discurso de legitimación del nuevo rumbo, examinando las características

\footnotetext{
5 Debemos destacar que ninguna tradición puede ser estudiada desde un esencialismo inmanente. Además, no puede ser entendida como plenamente sedimentada, sino que presenta, necesariamente, una sedimentación y objetivación parcial y relativa (Aboy Carlés, 2001; Barros, 2002, 2009). De este modo, las identidades y tradiciones pueden ser "reactivadas" o reformuladas por efecto del discurso (Laclau y Mouffe, 1987; Laclau, 2005).
} 
lingüísticas que asume el discurso presidencial para legitimarse políticamente frente a los dirigentes institucionales de tradición peronista.

\section{El menemismo y la estructura partidaria del justicialismo}

Una vez asumido el poder, en julio de 1989, el menemismo implementó las políticas de ajuste y reforma estructural del neoliberalismo, en un giro de timón frente a las políticas económicas y sociales de regulación del mercado e inclusión radicalizada, del peronismo de la segunda posguerra. En ese marco, rápidamente se produjo la emergencia de un fuerte discurso antimenemista, que asociaba a Menem y al menemismo con el neoliberalismo, al tiempo que lo contraponía a la tradición "nacional popular", vinculada, a su vez, con el peronismo de Perón. En esas circunstancias, a fines de 1989 se conformó un discurso antineoliberal en la estructura del partido, conocido como el "Grupo de los 8", que articularía un bloque de ocho diputados alternativos al menemismo. Estos diputados disidentes acusaban a Menem de haber "traicionado" al peronismo histórico ${ }^{6}$ (Gurrera, 2002).

En la etapa de sedimentación de la hegemonía neoliberal, sin embargo, el menemismo contaba con un amplio apoyo, o al menos un no cuestionamiento público, por parte de los enunciadores políticos clave del PJ, en relación con los ejes centrales del modelo económico. De este modo, se aceptaba como legítima la estabilidad monetaria, en tanto asociada equivalencialmente a la Ley de Convertibilidad (sancionada en abril de 1991) y las reformas neoliberales, y persistía un consenso general implícito sobre la no devaluación de la moneda (Fair, 2013). En ese marco, tras la definitiva disolución del Grupo de los ocho, se produciría una creciente moderación de los discursos de los enunciadores políticos más críticos. Estos dirigentes irían transformando sus discursos desde una orientación nacional popular antimenemista, con un eje central en defensa del nacionalismo económico antimperialista, una concepción mercadointernista y una visión democrático social-movimientista, hacia un posmenemismo, que prácticamente abandonaba estos elementos radicalizados y dejaba de vincular al menemismo con el neoliberalismo. En cambio, asumía, de forma predominante, su variación productivista nacional, con base en la defensa de la cadena equivalencial producción, trabajo e industria nacional (como en el caso de Eduardo Duhalde), mixturado con elementos "sensibilistas", frente a los costos sociales de las reformas (Antonio Cafiero, Ramón "Palito" Ortega) y, en ocasiones, sumando una crítica moralista a la corrupción menemista (Carlos "Chacho" Álvarez), o bien una variante eficientista contra el gasto político del Estado (José Octavio Bordón). En dichas circunstancias, las críticas del peronismo antimenemista a la "traición" de Menem y el

\footnotetext{
${ }^{6}$ Sus integrantes eran los diputados Carlos "Chacho" Álvarez, Germán Abdala, Juan Pablo Cafiero, Darío Alessandro, Luis Brunati, Franco Caviglia, Moisés Fontela y José "Conde" Ramos.
} 
discurso nacional popular radicalizado quedarían confinadas al discurso solitario de Moisés Fontela ${ }^{7}$. ¿Cómo legitimó el discurso menemista, tras el giro hacia el neoliberalismo, sus nuevos posicionamientos, frente a un partido que presentaba una fuerte tradición nacional popular?

\section{Las condiciones discursivas de posibilidad \\ 3.1. La sedimentación parcial de la tradición verticalista y pragmática del peronismo}

Antes de interiorizarnos en la construcción del discurso verbal de Menem, debemos considerar una serie de elementos extralingüísticos que actuaron como sus condiciones de posibilidad. Estos elementos discursivos, en un sentido amplio, condicionaron las características y particularidades que asumió el discurso menemista, así como las respuestas políticas de los enunciadores institucionales de tradición peronista. En primer lugar, desde el análisis del plano de las tradiciones parcialmente sedimentadas, debemos recordar la fuerte tradición de verticalismo y personalismo que caracterizó históricamente al peronismo. En efecto, el PJ ha sido, desde sus inicios, un partidomovimiento en el que la disciplina verticalista frente a las decisiones de los liderazgos y la acumulación de poder eran monedas corrientes. En ese marco, la idea de unidad y de lealtad partidaria resultaban cruciales (Martuccelli y Svampa, 1997), siendo estos significantes ampliamente replicados por sus enunciadores clave, en los discursos público-mediáticos previos al ascenso al poder de Menem (Fair, 2013). En segundo término, debemos considerar la fuerte tradición pragmática del peronismo, que presenta una doctrina ambigua y heterogénea (Sigal y Verón, 2003). Ambos elementos coadyuvaron a legitimar el giro neoliberal del presidente y a sedimentar la hegemonía menemista ${ }^{8}$.

\subsection{Los con-textos sociohistóricos y las prácticas sociales}

La segunda condición de posibilidad nos remite a elementos sociohistóricos vinculados con hechos físicos concretos, como el derrumbe del comunismo y la crisis del modelo benefactor keynesiano. En relación con el caso argentino, nos remite específicamente a la expresión corporal de la crisis del Estado Social, materializada en la efectiva burocratización, la ineficiencia y la corrupción del Estado. Estos elementos, lejos de ser meramente verbales, se hallaban parcialmente sedimentados en las

\footnotetext{
${ }^{7}$ Hemos analizado más en detalle la estructuración de estas discursividades y los posicionamientos de los diferentes enunciadores políticos clave en Fair (2013).

${ }^{8}$ Como lo resumirá el titular del bloque convencional del PJ, Augusto Alasino, el peronismo es "una forma de hacer las cosas", por lo que "nunca le interesó tener la propiedad de las ideas". Presenta en ese sentido, una tradición de "pragmatismo", lo que explica "la eficacia del peronismo" (Página 12, 03-07-94).
} 
prácticas sociales de la vida cotidiana de los sujetos, lo que permitía reforzar la construcción de un nuevo sentido común en torno a la reducción del papel interventor del aparato estatal. Además, los con-textos nos conducen a la inflación del período 1984-1988 y a la hiperinflación de 1989 y 1990. En ese sentido, debemos destacar el efectivo control de la tasa de inflación, materializado en el proceso de estabilización de la moneda que realizó el menemismo, a partir de la sanción de la Convertibilidad, en 1991. Finalmente, la reactivación económica inicial y la modernización tecnológica que produjo la estabilización de los precios, el ingreso de inversiones y el incremento del crédito, en el marco de su materialización física en las prácticas sociales (precios estables, acceso al crédito barato, ampliación del consumo), también coadyuvaron al éxito del discurso de sentido común de Menem (Fair, 2013).

Un último elemento nos conduce al proceso de creciente institucionalización del justicialismo. En efecto, a partir de la derrota del peronismo en manos del radicalismo alfonsinista, en 1983, se había llevado a cabo una paulatina reorganización dentro del justicialismo, la cual condujo a una escisión interna. Esta fractura interna con los "Mariscales de la derrota" concluyó en la formación, un año después, del Movimiento de Renovación, más conocido como "renovación peronista". Esta vertiente representaba el ala más liberal democrática del partido, frente a la ortodoxia peronista y su concepción en mayor medida movimientista-populista. No obstante, tras la sorpresiva derrota de Antonio Cafiero a manos de Carlos Menem, en las elecciones internas del PJ realizadas en julio de 1988, la corriente renovadora se encolumnará detrás del proyecto menemista (Palermo y Novaro, 1996; Palermo, 1999; Aboy Carlés, 2001).

Los elementos extralingüísticos que hemos mencionado, vinculados con condicionamientos institucionales, físicos, sociohistóricos e identitarios y con prácticas sociales determinadas, no deben ser considerados como determinantes extradiscursivos, sino analizados en el marco de la creciente sedimentación local y global del discurso neoliberal, un discurso que asociaba la caída del comunismo con el fracaso del "autoritarismo" y el triunfo de la paz y la libertad, propias de la democracia liberal; que se refería al fracaso del keynesianismo a nivel mundial y destacaba la necesidad de insertarse en el orden global y aplicar las reformas de mercado y que promovía el consumo como modalidad predominante de identificación, asociado a una idea de libertad de elección y de felicidad para el individuo y a toda una lógica positivista vinculada con el progreso y la modernización de las sociedades (Fair, 2013).

\section{Las estrategias interpelativas del discurso de Menem frente a la tradición peronista: el doble mandato de "aggiornamiento" y "actualización" partidaria}

Una vez asumido, y tras su "giro de 180 grados" hacia las reformas neoliberales, Menem debía revalidar su credencial como peronista, para mantener el apoyo efectivo 
de la estructura peronista. En ese contexto, como señalamos, contaba con la ventaja del clásico pragmatismo ideológico del partido-movimiento. En ese marco, lejos de desvincularse de toda relación con la tradición peronista, el presidente se reapropiaría de forma selectiva de la tradición pragmática, para expresar que su proceso de "transformación nacional" y "revolución pacífica" se hallaba inmerso dentro de la más pura tradición peronista, pero que ahora se había "actualizado" o aggiornado a los múltiples cambios generados a nivel mundial". En la necesidad de "modernizar la Constitución" se legitimaría también el intento de reformarla para lograr la reelección presidencial, prohibida por una cláusula de la Carta Magna ${ }^{10}$. A partir de allí, desde el plano de la construcción de la hegemonía, el discurso menemista planteaba una doble "actualización" identitaria del peronismo:

- Por un lado, se debía realizar un "aggiornamiento" político-institucional, en el que el peronismo, siguiendo la tarea iniciada por la renovación peronista desde el gobierno de Alfonsín, debía abandonar la lógica populista-movimientista de la segunda posguerra, para incorporar la aceptación del "conflicto", la "libertad", la "paz", la "pluralidad" y el "disenso"11. En ese marco, Menem se posicionaba desde el Perón "herbívoro" que retornaba del exilio en 1973 para unificar a la Nación (Sigal y Verón, 2003), enfatizando el elemento de "unidad" y "pacificación" del "último" Perón y su lógica de interpelación más amplia, que buscaba también la unidad de los "argentinos", por sobre la de los "peronistas". En un contexto de expansión mundial de la democracia liberal, el discurso presidencial asumía la necesidad de realizar un "cambio cultural", que abandonara la lógica movimientista, posicionándose dentro de los valores liberal-democráticos, los mismos que eran defendidos por los dirigentes provenientes de la renovación peronista. De este modo, el presidente retomaba una de las demandas primordiales de los exponentes de la renovación de 1988, referidas a la necesidad de promover una mayor democratización partidaria, abandonando las habituales prácticas "autoritarias" y "violentas" de la ortodoxia del partido"

\footnotetext{
${ }^{9}$ En palabras de Menem, "este Gobierno y este Presidente están haciendo lo que hubiese hecho Perón si le hubiera tocado gobernar la Argentina en esta época" (La Nación, 29-03-93, p. 5). Incluso, en una oportunidad, el presidente llegaría a destacar que el menemismo "no existía" como tal, y que él se consideraba, en realidad, un "peronista" (véase Fair, 2013).

${ }^{10}$ Declaraciones de Carlos Menem reproducidas en Clarín, 01-03-93, p. 7.

${ }^{11}$ En palabras de Menem, "la libertad de expresión ha sido una de las manifestaciones más sensibles del modo de vida de la democracia argentina, y nadie puede negar que se ha ejercido sin cortapisas. Los argentinos estamos cimentando el respeto a las ideas del otro, el cumplimiento de las leyes, el acatamiento a la Justicia y la convivencia en un disenso clarificador" (Página 12, 16-06-93, p. 4).

${ }^{12}$ Entre ellos, se destacaban los discursos de los principales exponentes de la renovación: Antonio Cafiero y José Manuel de la Sota. En el caso del entonces gobernador de Buenos Aires, afirmaba que "el entorno que
} 
- La segunda de las "actualizaciones", que nuevamente seguía la tradición peronista, era la económica. En ese marco, las alocuciones de Menem apelaban a un discurso positivista-evolucionista, en el que había que "adaptar" el peronismo a las reformas neoliberales. Al mismo tiempo, relegaba al peronismo de posguerra a lo "antiguo" y "atrasado", destacando la necesidad de "modernizar" y "aggiornar" al partido a los "nuevos tiempos"13. Esta "modernización" se articulaba, a su vez, con el fenómeno de la globalización económica y la interconexión mundial, de manera tal que ahora, en el marco de la Tesis del Fin de la Historia, había que abandonar la economía "cerrada" y "aislada" del peronismo de la segunda posguerra, e "insertarse" al nuevo mundo "pacífico" y "solidario" de la "aldea global" (Fair, 2011, 2013).

\section{El juego dialógico con los referentes institucionales de la estructura partidaria del justicialismo}

\subsection{Las demandas sensibilistas de los referentes posmenemistas del justicialismo}

¿Qué ocurría con los discursos de los referentes institucionales de la estructura territorial del PJ? A finales de los años 80, uno de los reclamos centrales de los gobernadores peronistas se concentraba en la no coparticipación del Gobierno Nacional de los fondos a sus administraciones, lo que impedía abonar los salarios de los empleados públicos provinciales. De un modo más general, en la estructura del justicialismo se presentaba un macro-discurso nacional popular que defendía los derechos sociolaborales de los trabajadores, criticando los efectos regresivos de la inflación, las políticas económicas contra el Estado Social y la lógica de especulación financiera (Fair, 2013). Una vez que Menem asumió el poder, sobre todo a partir de los efectos regresivos de las reformas neoliberales, las demandas privilegiadas de los gobernadores peronistas comenzarían a girar en torno a la cuestión social, reclamando la incorporación de mayor "sensibilidad" al modelo. Así, en la etapa de sedimentación de la hegemonía menemista, Ramón "Palito" Ortega, gobernador de Tucumán, apoyaba

rodea a Menem es un grupo incoherente, donde se juntan figuras que vienen del montonerismo, con colaboradores de López Rega y otros compañeros de la derrota" (Clarín, 10-04-88, p. 10). Además, se refería al "clima de violencia, intolerancia, presencia de barras bravas y agresiones patoteriles, que preanuncian el resurgimiento de metodologías repudiables, que llevaron al peronismo al descrédito y a la derrota y que motivaron el nacimiento de la renovación" (Clarín, 21-03-88, p. 17). De la Sota, por su parte, afirmaba que "Cafiero y yo somos la máxima garantía de que no habrá repeticiones de conductas antidemocráticas en el peronismo" (Clarín, 21-03-88, p. 12).

${ }^{13}$ En ese marco, Menem afirmaba que "algunos sectores de mi partido, que no digieren esta economía moderna, están con una actitud nostálgica, queriendo volver 40 o 50 años atrás" (Clarín, 13-05-93, p. 20). 
la "estabilidad", pero reclamaba incorporarle mayor "crecimiento", que "traiga alivio y mejores perspectivas a los que menos tienen". En ese marco, se debía promover una economía "sensible, que no olvide nunca que su real destinatario es el hombre" ${ }^{14}$. Eduardo Duhalde, gobernador de Buenos Aires, también apoyaba la "estabilidad que hemos logrado", pero ahora debía "transformarse en otra cosa, en más trabajo ${ }^{15}$. Finalmente, José Octavio Bordón, gobernador de Mendoza, junto a un discurso eficientista que buscaba ser la "continuidad de Menem", también coincidía con el resto de los enunciadores posmenemistas en que "no se puede estar gobernando solamente con la estabilidad, sino que hay que buscar otros valores importantes". En ese contexto, destacaba que "el menemismo se ha alejado de las inquietudes sociales", ya que "las reformas del Estado se han convertido nada más que en privatizaciones"16. En otra oportunidad, señalará que "estamos faltos de una política social general"17. Sin embargo, pese a las críticas sensibilistas, en estos discursos, al igual que en otros referentes del partido, no se construirán alternativas en el plano de las políticas públicas, compartiendo plenamente la defensa de la estabilidad económica (Fair, 2013).

\subsection{Los planes focalizados como respuesta a las demandas sensibilistas de los discursos de los enunciadores de tradición peronista}

Aunque en la Argentina las políticas sociales nunca fueron plenamente universales, conteniendo diversos componentes "meritocráticos" y "corporativos" (Lo Vuolo y Barbeito, 1998; Lo Vuolo, 2001: 62), el peronismo incorporó una lógica de ampliación de los derechos sustantivos, garantizando "efectivas condiciones de integración y tendencias igualitarias" (García Delgado, 2003: 159). Luego del giro hacia las políticas ortodoxas, durante la dictadura cívico-militar del período 1976-1983, el gobierno de Alfonsín implementó el denominado Programa Alimentario Nacional (PAN) (Grassi, 2004: 171). En ese contexto, las políticas asistencialistas, inscriptas dentro del paradigma neoliberal, venían sedimentándose desde la década de los 80 .

Durante el gobierno de Menem, sobre todo a partir de 1992-1993, comenzaron a sentirse con fuerza los efectos regresivos de las reformas y ajustes neoliberales ${ }^{18}$. En ese marco, emergió un discurso, a tono con los tiempos, que colocaba el eje en aspectos "sensibilistas", tendientes a la "humanización" del modelo. Como una respuesta política a estas "demandas sociales insatisfechas" (Laclau, 2005) sobre la cuestión social, a partir de 1991, y sobre todo desde 1993, el gobierno de Menem implementará, en el plano

\footnotetext{
${ }^{14}$ Ramón "Palito" Ortega, "El tren de la historia, nota en La Nación, 20-05-93, p. 9.

${ }^{15}$ Eduardo Duhalde, Página 12, 08-06-93, p. 8.

${ }^{16}$ José Bordón, Clarín, 18-05-88, p. 4

17 José Bordón, Clarín, 24-03-88, p. 14.

${ }^{18}$ A partir de 1992, se redujo el índice de empleo por tiempo completo y, a partir de 1993, la ocupación total dejó de crecer (Lo Vuolo: 2001: 58).
} 
del discurso (en sentido amplio), un conjunto de planes focalizados, basados en una lógica de asistencia social ${ }^{19}$ (Cao, 2007; De Valle, 2008). Además, otorgará créditos baratos y rebajas impositivas a aquellos gobernadores que implementaran las políticas de reforma estructural. Finalmente, para lograr el apoyo a sus políticas neoliberales, incorporará nuevos "atenuantes" económicos de las reformas, entre ellos, transferencias financieras de corto plazo, adelantos de coparticipación de ingresos y fondos fiduciarios a los gobernadores que se disciplinaran al menemismo (Bonvecchi, 2004: 8284). Esta matriz política no solo moderará los costos del ajuste, sino que, incluso, en una primera etapa, creará mayor empleo ${ }^{20}$, promoverá un incremento de la inversión provincial $y$, en algunas regiones, una mejora de la actividad económica ${ }^{21}$. Además, debemos destacar el complejo juego de negociación político-institucional que aplicará el menemismo en relación con las privatizaciones del petróleo y los fondos de jubilación y pensión ${ }^{22}$.

\subsubsection{El discurso de legitimación de las políticas públicas focalizadas}

Ahora bien, las prácticas político-institucionales, como todo hecho social, solo pueden ser entendidas en el marco de determinado discurso verbal (o textual) que le otorga significación social a las percepciones y a las propias prácticas extralingüísticas ${ }^{23}$ (Laclau y Mouffe, 1987). En ese contexto, que nos aleja de los enfoques de la Teoría de la Elección Racional, habitualmente aplicados a este tipo de estudios sobre las políticas públicas, algunos trabajos se han referido a la temprana construcción de la cuestión social desde el discurso neoliberal (Ezcurra, 1998). En ese sentido, Grassi (2004: 178 y ss.) ha destacado que, ya desde 1990, existía en los organismos multilaterales de crédito un discurso estructurado sobre la "cuestión social", asociado a la necesidad de crear una "malla de seguridad" frente a los efectos regresivos de las reformas. En lo que refiere al caso argentino, la autora observa, además, la presencia de un discurso que podemos denominar monetarista, en el que el gasto social era vinculado con el aumento de la inflación y el desbarajuste fiscal (Grassi, 2004). Pero la sedimentación de

\footnotetext{
${ }^{19}$ En ese sentido, se aplicarán políticas de "integración regional" (Cao, 2007), a través de más una veintena de planes de asistencia social focalizada (Plan Social, Fondo Nacional de Viviendas, etc.) (Del Valle, $2008: 26$ y ss.).

${ }^{20}$ Mientras que el empleo público nacional se redujo cerca de un 15 \% entre 1991 y 1993 , el empleo público en la administración provincial creció un 9 \%, entre 1991 y 1995 (Página oficial del SIARE).

${ }^{21}$ Cabe destacar, de todos modos, que los sectores más beneficiados serán, en prácticamente todas las provincias, los dos quintiles más altos de la población (MEyOSP, 2004).

22 Este juego incluirá el otorgamiento de regalías a las provincias petroleras, derivadas de la futura privatización de la empresa YPF. Además, el menemismo diferirá las políticas de desregulación comercial y excluirá de la privatización previsional a las administraciones provinciales, dejando intactos los fondos de los gobernadores (Gerchunoff y Torre, 1996: 757; Alonso, 2000; Etchemendy, 2001).

23 Ello no implica, sin embargo, que el discurso verbal y las prácticas sociales (pese a ser siempre discursivas) no puedan ser analíticamente diferenciables.
} 
esta concepción liberal-conservadora encuentra antecedentes que se remontan al período de desarrollismo posperonista. Así, por ejemplo, la dictadura militar de Onganía (1966-1970) ya presentaba una visión "negativa" de la "cuestión social", la misma que luego asumiría la dictadura del 76 (Laguado Duca, 2011). Los discursos (en sentido amplio) que predominarán durante el gobierno de Alfonsín, relegarán esta visión neoconservadora sobre lo social, aunque retomarán varios de los ejes del monetarismo, como la crítica al gasto público como causante de la inflación y el déficit fiscal $^{24}$ (Fair, 2013).

En ese contexto de creciente sedimentación de la ortodoxia neoliberal, un proceso que luego se vería profundizado por la "violencia inflacionaria" (Bonnet, 2008) de 1989, desde las alocuciones de Menem se promoverá un discurso en el que la "cuestión social" era reformulada partiendo de un discurso de tradición peronista, para ser articulada dentro del paradigma neoliberal. Desde el análisis del juego dialógico con los referentes institucionales de tradición peronista, lo que hará el discurso menemista, en ese sentido, será reformular y "adaptar" las demandas existentes, para rearticularlas a su proyecto neoliberal. Así, según Menem, las políticas asistencialistas eran equivalentes a la incorporación de un principio de "justicia social". Ello reenviaba a la tradición nacional popular reformista del peronismo, de modo tal que se incorporaba al modelo la "cuestión social"25.

En la misma sintonía, la implementación del denominado Plan Social, a comienzos de 1993, era posible porque, según Menem, ahora "tenemos recursos". En esas circunstancias, el plan focalizado era significado como una "marcha" hacia "el encuentro de los pobres", que permitía "combatir la pobreza"26. De este modo, el modelo satisfacía las demandas de los "sectores más postergados del país", garantizando el derecho a la "salud", el "trabajo" y la "educación". Estos elementos se articulaban, a su vez, con significantes centrales de la tradición peronista, y habituales en los discursos peronistas de finales de los años 80 (Fair, 2013), como la defensa del trabajo y la inclusión social. De este modo, eran rearticulados a la presencia de un modelo con "justicia social", que promovía "un país sin excluidos"27. Finalmente, en sus discursos, Menem relacionaba el Plan Social con la "lucha contra la pobreza",

\footnotetext{
${ }^{24}$ Sin embargo, el discurso de estos enunciadores, con la excepción de Angeloz, así como las prácticas discursivas del gobierno, presentaban aún residuos heterodoxos, al punto tal que se mantenía un acuerdo de precios con el empresariado para controlar la tasa de inflación.

${ }^{25}$ La justicia social representa uno de los principios básicos del peronismo, junto a la soberanía política y la independencia económica.

${ }^{26}$ Carlos Menem, en Página 12,07-04-93, p. 2. Cabe destacar que, si bien Menem insistirá en que la pobreza se había reducido a partir de 1991, algunos análisis académicos señalan que estos datos solo se expresaban en la metodología oficial de medición de la pobreza, ya que todas las mediciones externas mostraban variaciones en el sentido contrario (véase Lo Vuolo, 2001: 62).

${ }^{27}$ Propaganda de la Presidencia de la Nación, Clarín, 18-04-93, pp. 16-17.
} 
enmarcándola en una "auténtica política social", que "supera hoy las burdas fronteras de la dádiva, la prebenda o la limosna"28.

En otros casos, frente a las demandas sensibilistas en reclamo por los "costos sociales" del ajuste, se apelaba a otros significantes típicos del peronismo. Así, en su alocución de apertura de la Asamblea Legislativa, el 1 de mayo de 1993, el discurso de Menem se refería a significantes como el "federalismo" y a la tesis del "país real", afirmando que "el período 1993-1995 tiene que ser el tiempo de las economías regionales. El tiempo de todos los sectores asociados a la Argentina real y federal". De este modo, nuevamente reformulaba los discursos críticos de la pobreza, vinculando los planes focalizados con un proceso de inclusión social de los trabajadores que, además, fomentaba el federalismo.

Desde las propagandas mediáticas del gobierno, por su parte, los planes focalizados eran vinculados con una "transformación estructural del Estado", que se basaba en la "racionalización de los organismos" y la "optimización de los recursos". En ese marco, el denominado Plan Arraigo se articulaba a la "federalización de los fondos nacionales aplicables a políticas sociales", aunque incluyendo valores adicionales, como la defensa de la "estabilidad económica". Además, se lo posicionaba dentro de un "redimensionamiento del Estado", que promovía un "profundo sinceramiento", todo lo cual permitía "conocer la verdadera relación entre el Estado y su comunidad". En dichas circunstancias, el "programa arraigo" constituía "la voluntad y la acción del Gobierno Nacional para la definitiva propiedad de la tierra para la vivienda" ${ }^{29}$.

\subsection{El juego de articulación de la estabilidad con los planes focalizados y la cadena equivalencial de justicia social, crecimiento, aumento del trabajo y de la producción}

Hemos señalado que la estabilidad monetaria se convertiría en una condición de posibilidad de la conformación del discurso menemista. En efecto, la implementación de la Ley de Convertibilidad, en abril de 1991, había logrado estabilizar con éxito los precios y reactivar la economía, al menos en comparación con los devastadores indicadores de finales de los años 80 . En ese marco, desde el discurso presidencial, la estabilidad se construía como equivalente a la Convertibilidad, y ambas, al logro de una moneda "sana" y "fuerte" ${ }^{30}$, que había permitido una efectiva estabilización de los precios. Ello permitía, bajo el prisma de indicadores económicos que se materializaban en las prácticas cotidianas, el retorno de la "confianza" en la moneda nacional ${ }^{31}$ y promovía el crecimiento, la "modernización" y el acceso a un proceso de "inserción

\footnotetext{
${ }^{28}$ Carlos Menem, La Nación, 02-05-93, p. 13.

${ }^{29}$ Propaganda de la Presidencia de la Nación por motivo del Plan Arraigo, Clarín, 09-07-93, p. 5.

${ }^{30}$ Carlos Menem, Página 12, 17-10-91 y discurso oficial del 29-12-93, p. 279, entre otros.

${ }^{31}$ Carlos Menem, Discursos oficiales del 29-08-91, p. 159, 29-04-93, p. 202 y 20-09-93, pp. 398-399.
} 
inédito" de la Argentina al orden internacional. De este modo, se producía una fuerte articulación entre los significantes estabilidad = convertibilidad = "confianza" = moneda "sana" y "fuerte" = crecimiento = modernización $=$ inserción internacional (Fair, 2013).

En segundo lugar, desde el discurso de Menem, la estabilización monetaria había terminado definitivamente con las prácticas corrientes del período alfonsinista, basadas en el desabastecimiento de combustibles, la remarcación diaria de mercaderías y la compra de divisas para resguardarse de la inflación. En ese marco, a partir del éxito de la Convertibilidad, el presidente afirmará que había logrado concluir con una larga historia de "especulación", "caos" y "desorden". De esta forma, la estabilidad se presentaba como una respuesta política frente a las críticas a la especulación financiera, habituales en los discursos de los dirigentes de tradición peronista, de finales de los años $80^{32}$ (Fair, 2013).

Pero además, el discurso verbal menemista desarticulaba la defensa de la producción y el trabajo de las cadenas nacional populares, para rearticularlas a las reformas neoliberales. En ese marco, la estabilidad, junto a la "modernización", adosada a las reformas de mercado, promovía el crecimiento de la "producción" y el "trabajo", frente a la "especulación financiera" y la "desvalorización salarial", que generaba la inflación ${ }^{33}$. De este modo, a través de la articulación de la inflación a un "impuesto inflacionario" que reducía los salarios y aumentaba los índices de pobreza, el discurso de Menem lograba asociar la estabilidad monetaria con una respuesta efectiva a los frecuentes reclamos de la estructura partidaria del Justicialismo de finales de los años 80, que se expresaban en defensa de los salarios de los trabajadores y críticos de los efectos regresivos de la inflación sobre sus condiciones de vida, sin construir una alternativa superadora (Fair, 2013). En el contexto de una estabilización efectiva de los precios $^{34}$, el presidente legitimaba el encadenamiento de la estabilidad a un elemento de "transformación" en el plano social, vinculado, desde su perspectiva, con el clásico componente de "justicia social" que caracterizaba al peronismo de la segunda posguerra $^{35}$.

\footnotetext{
${ }^{32}$ Ello no implica desconocer las nuevas modalidades que adquirió la especulación financiera en los años 90, centrada en la fuga de capitales para valorizarlos en los bancos internacionales (véase Basualdo, 2000).

${ }^{33}$ Discurso oficial de Carlos Menem del 20-09-93, pp. 398-399. Véase también discurso oficial del 10-0793, p. 69.

${ }^{34}$ Aunque no es motivo de análisis del presente trabajo, hemos destacado previamente que los indicadores expuestos por el presidente tenían una base "material" en las prácticas sociales de los sujetos, de modo tal que la estabilidad reforzaba su eficacia como significante asociado al control de precios, ya que el control de precios era efectivo en las prácticas extralingüísticas de la vida cotidiana (véase Fair, 2013).

${ }^{35}$ Desde sus primeros discursos en el poder, Menem afirmaba que "el principal enemigo contra la justicia social es la hiperinflación, que devora salarios y bienestar en millones de hogares argentinos" (Discurso oficial del 09-07-89, p. 17), y lo consideraba el "impuesto más regresivo e injusto entre los argentinos" (Discurso oficial del 19-07-91). Véase también discursos oficiales del presidente del 03-07-91, p. 18 y 0508-91, pp. 95-96.
} 
Finalmente, esta amplia articulación en torno al "punto nodal" (Laclau y Mouffe, 1987) estabilidad se enganchaba con las políticas asistencialistas, inscriptas dentro de la matriz neoliberal (Ezcurra, 1998), sin dejar de legitimarse en un discurso de tradición productivista peronista. Así, desde el discurso verbal de Menem, estas políticas públicas permitían generar nuevas "fuentes de trabajo a quienes se van quedando sin el mismo". De este modo, permitían el fortalecimiento de la "estabilidad" y, en el marco del control inflacionario, promovían una "verdadera y auténtica justicia social". Ello reenviaba, finalmente, a una "comunidad" que "trabaja" y que "lucha contra la pobreza" ${ }^{36}$. De este modo, la rearticulación de la estabilidad se asociaba a otro significante clave de los discursos nacional-populares de finales de los años 80 como es el trabajo, al tiempo que se reforzaba su vinculación con el componente básico del peronismo en defensa de la justicia social.

\section{Conclusiones}

Colocando el eje en el plano de la construcción de la hegemonía, analizamos en este trabajo el juego dialógico de interacción entre el discurso verbal menemista y los discursos de los referentes institucionales de tradición peronista. Para ello, asumimos una postura de análisis del discurso en un sentido amplio, incluyendo el estudio de los elementos lingüísticos, pero también haciendo mención a los componentes extralingüísticos, que actuaron con sus condiciones discursivas de posibilidad. Destacamos que el discurso verbal del presidente adquiría legitimidad bajo ciertos condicionamientos institucionales, sociohistóricos, económicos e identitarios, y bajo ciertas prácticas sociales parcialmente sedimentadas, que actuaban como sus condiciones de posibilidad. A partir de estos condicionamientos, el discurso de Menem instaba a realizar una transformación cultural en la estructura partidaria del peronismo, que debía llevar a cabo un doble mandato evolutivo. Por un lado, asumiendo la tradición pragmática del peronismo, debía abandonar la visión mercadointernista y de nacionalismo económico antimperialista, adaptándose a los nuevos tiempos de globalización y reformas estructurales. Por el otro, continuando con el discurso liberaldemocrático parcialmente sedimentado en los enunciadores de tradición peronista renovadora, debía abandonar la tradición movimientista-populista y asumir plenamente los valores de la democracia liberal. Desde el discurso verbal de Menem, ambos elementos se vinculaban con la necesidad de garantizar la permanencia de la estabilidad económica y de moderar los antagonismos exacerbados de épocas previas. En ese marco, el discurso evolucionista, liberal y pacifista del presidente realizaba una articulación equivalencial entre las reformas de mercado, la estabilidad monetaria, la

\footnotetext{
${ }^{36}$ Carlos Menem, discurso oficial del 01-05-93, p. 225.
} 
Convertibilidad, el fenómeno de la globalización y la democracia, en su concepción representativa liberal y neoconservadora en lo social.

En una segunda parte, nos concentramos en el análisis específico de lo que definimos como el juego dialógico entre el discurso de Menem y las discursividades de los principales exponentes institucionales del justicialismo. En ese marco, examinamos las estrategias presidenciales tendientes a la reapropiación, desarticulación, reformulación y rearticulación de las demandas privilegiadas de la estructura partidaria del justicialismo. Posicionándonos en la etapa de sedimentación de la hegemonía menemista, destacamos que el discurso menemista, en el contexto del crecimiento de la pobreza, la desocupación y la subocupación, respondía a las demandas privilegiadas de los enunciadores de tradición nacional popular peronista, quienes reclamaban por una mayor sensibilidad social (especialmente, los gobernadores posmenemistas), mediante una reformulación de los discursos existentes. Así, frente a los costos sociales del modelo, en el contexto de creciente sedimentación de la concepción neoliberal, promovía una política social asistencialista y focalizada. Desde el discurso de legitimación del presidente, los planes focalizados permitían satisfacer las demandas insatisfechas de los sectores sociales más postergados, incluyéndolos en el modelo. De este modo, como ahora había recursos económicos, se podían garantizar el derecho a la salud, el trabajo y la educación, valores centrales del peronismo histórico. Además, estos elementos se articulaban de manera equivalencial con una promesa evolucionista de reducción a futuro de la pobreza y de generación de un mayor empleo, por lo que el modelo incorporaba una defensa de la justicia social, promoviendo un país sin excluidos. Mediante este juego dialógico, que mostraba al presidente como un dirigente que "escuchaba" y recogía las demandas sociales de la dirigencia del justicialismo, las políticas neoliberales se articulaban con significantes centrales de la tradición peronista, y habituales en los discursos de sus más destacados referentes político-partidarios. En otros casos, se incorporaban otros significantes típicos del discurso nacional popular peronista, asociando los planes asistencialistas con el federalismo y la integración de la Argentina real. De este modo, se reformulaban los discursos críticos de la pobreza, rearticulándolos a una nueva red de significaciones asociadas a las políticas neoliberales y neoconservadoras, que promovían un proceso de inclusión social de los trabajadores que, además, fomentaba el federalismo y garantizaba un principio de justicia social.

Finalmente, el discurso de mixtura neoliberal-peronista de Menem encadenaba sus políticas públicas, entre ellas los planes asistencialistas, al éxito de la estabilidad de la moneda, producto de la Convertibilidad. Ello permitía acceder, en el contexto de indicadores positivos de estabilización materializados en las prácticas cotidianas, a una "economía social de mercado" o "economía popular de mercado", que había logrado, a partir de 1991, una reducción efectiva de los índices de pobreza, una expansión del consumo popular y un fomento a la producción nacional y el trabajo, concluyendo, 
desde el discurso de Menem, con la especulación financiera y la desvalorización de los salarios de los trabajadores. El logro efectivo de la estabilidad monetaria, en ese sentido, permitía reducir el incremento de los índices de pobreza que generaba el "impuesto inflacionario", por lo que tanto la estabilidad de precios, como los planes focalizados incorporaban al modelo la defensa de la justicia social, reenviando a un elemento central de la tradición peronista.

De este modo, mediante el juego dialógico de desarticulación, reformulación y rearticulación de significantes y cadenas equivalenciales, el discurso de Menem, al tiempo que construía un modelo de país que era económicamente concentrador y socialmente excluyente, no dejaba de incorporar un principio legitimador sobre la "cuestión social", que buscaba situarse como una continuidad del proceso de inclusión radicalizada del peronismo de la segunda posguerra. Las interpelaciones del discurso menemista contribuían, así, bajo las mencionadas condiciones discursivas de posibilidad, a reformular el discurso nacional popular de tradición peronista y a sedimentar un nuevo sentido común en torno a las políticas neoliberales.

\section{Bibliografía}

AA.VV (1993). Cuesta abajo. Los nuevos pobres: efectos de la crisis en la sociedad argentina, Bs. As.: Losada-UNICEF (pp. 119-142).

Aboy Carlés, Gerardo (2001). Las dos fronteras de la democracia argentina. La reformulación de las identidades políticas de Alfonsín a Menem, Rosario: Homo Sapiens.

Alonso, Guillermo (2000). Política y seguridad social en la Argentina de los '90. Madrid: Mino y Dávila.

Azpiazu, Daniel (1995). La industria argentina ante la privatización, la desregulación y la apertura asimétricas de la economía. La creciente polarización del poder económico. En D. Azpiazu y H. Nochteff (Edits.), El Desarrollo ausente (pp. 157-233), Bs. As.: TesisNorma-FLACSO.

Bajtín, Mijaíl (1982). El problema de los géneros discursivos. En Estética de la creación verbal, México: Siglo XXI (pp. 248-293).

Balsa, Javier (2011). Aspectos discursivos de la construcción de la hegemonía, Identidades, 1, 70-90. URL: http://iidentidadess.files.wordpress.com/2011/03/4identidades-1-1-2011-balsa.pdf

(2013). "Cuatro planos de análisis de las operaciones discursivas en la construcción de la hegemonía". Ponencia presentada en el "VI Coloquio de Investigadores en Estudios del Discurso y II Jornadas Internacionales sobre Discurso e Interdisciplina", Asociación Latinoamericana de Estudios del Discurso (ALED), 12 al 14 de junio de 2013, Bs. As.: Bernal.

Barros, Sebastián (2002). Orden, democracia y estabilidad. Discurso y política en la Argentina entre 1976 y 1991. Córdoba: Alción. 
(2009). Las continuidades discursivas de la ruptura menemista. En F. Panizza (comp.), El populismo como espejo de la democracia, Bs. As.: FCE (pp. 351-381).

Basualdo, Eduardo (2000). Concentración y Centralización del capital en la Argentina durante la década de los noventa. Bs. As.: UNQUI.

Beccaria, Luis (2002). Empleo, remuneraciones y diferenciación social en el último cuarto del siglo XX. En VVAA, Sociedad y sociabilidad en la Argentina de los 90 (pp. 2754), Bs. As.: Biblos.

Bonnet, Alberto (2008). La hegemonía menemista. El neoconservadurismo en Argentina. 1989-2001. Bs. As.: Prometeo.

Bonvecchi, Alejandro (2004). La eficacia de las inconsistencias: teoría y práctica del gobierno de la economía. En M. Novaro y V. Palermo (comps.), La historia reciente. Argentina en democracia. (pp. 75-90), Bs. As.: Edhasa.

Canelo, Paula (2002). La construcción de lo posible: identidades y política durante el menemismo. Argentina, 1989-1995, Bs. As.: Documento de trabajo de FLACSO.

(2011). "Son palabras de Perón". Continuidades y rupturas discursivas entre peronismo y menemismo". En A. Pucciarelli (coord.), Los años de Menem, Bs. As.: Siglo XXI (pp. 71-111).

Cao, Horacio (2007). Las políticas regionales en la Argentina de los '90. Documentos y aportes en administración pública y gestión estatal, 8, 27-51.

Castellani, Ana y Gaggero, Alejandro (2011). Estado y grupos económicos en la Argentina de los '90, en A. Pucciarelli (coord.), Los años de Menem. Bs. As.: Siglo XXI (pp. 263-292).

Del Valle, Alejandro (2008). Política social focalizada y construcción de una red social. Lecciones de la experiencia argentina. Estudios Sociales, 16, 32, 11-58.

Etchemendy, Sebastián (2001). Construir coaliciones reformistas: La política de las compensaciones en el camino argentino hacia la liberalización económica, Desarrollo Económico, enero-marzo.

Ezcurra, Ana María (1998). ¿Qué es el neoliberalismo? Evolución y límites de un modelo excluyente. Bs. As.: Ideas.

Fair, Hernán (2011). El mito de la aldea global en el discurso menemista. Revista Argentina de Sociología, 15/16, 53-80.

(2013). La construcción y legitimación social de la hegemonía menemista. Política, discurso e ideología entre 1988 y 1995. Tesis para optar al grado de Doctor en Ciencias Sociales, Universidad de Buenos Aires (UBA), Bs. As., 416 pp. (inédito).

Fairclough, Norman (2003). Analyzing Discourse, Great Britain: Routledge.

Foucault, Michel (2008). La Arqueología del Saber, México: Siglo XXI.

García Delgado, Daniel (2003). Estado-Nación y la crisis del modelo: el estrecho sendero, Bs. As.: Norma.

Gerchunoff, Pablo y Torre, Juan Carlos (1996). La política de liberalización económica en la administración de Menem. Desarrollo Económico. 141, 733-768. 
Giddens, Antony (1993). La constitución de la sociedad, Madrid: Alianza.

Giosa Zuazúa, Noemí (2007). Transformaciones y tendencias del mercado de empleo en Argentina. Entre el desempleo y el empleo precario. En K. Forcinito y V. Basualdo (comps.), Transformaciones recientes en la economía argentina, Bs. As.: Prometeo-UNGS.

Grassi, Estela (2004). Política y cultura en la sociedad neoliberal. La otra década infame. Bs. As.: Espacio editorial.

Gurrera, María Silvana (2002). Protesta, conflicto sindical e identidades políticas: la Central de los Trabajadores Argentinos en los años noventa, Informe final del concurso: Movimientos sociales y nuevos conflictos en América Latina y el Caribe, Bs. As.: CLACSO. URL: http://bibliotecavirtual.clacso.org.ar/ar/libros/becas/2002/mov/gurrera.pdf

Howarth, David (2010). Discourse, Great Britain: Open University Press.

Isuani, Aldo (1996). Anomia social y anemia estatal. Sobre integración social en la Argentina, Sociedad 10, FCS-UBA, Bs. As.

Laclau, Ernesto y Mouffe, Chantal (1987). Hegemonía y estrategia socialista. Hacia una radicalización de la democracia. Bs. As.: FCE.

Laclau, Ernesto (2005). La Razón populista. Bs. As.: FCE.

Laguado Duca, Arturo (2011). La construcción de la cuestión social. el desarrollismo post-peronista. Bs. As.: Espacio editorial.

Levitsky, Steven (2005). La transformación del justicialismo. Del partido sindical al partido clientelista, 1983-1995. Bs. As.: Siglo XXI.

Lo Vuolo, Rubén (2001). Alternativas. La economía como cuestión social, Bs. As.: Altamira.

Lo Vuolo, Rubén y Barbeito, Alberto (1998). La nueva oscuridad de la política social, Bs. As.: Miño y Dávila editores.

Martuccelli, Danilo y Svampa, Maristella (1997). La Plaza vacía. Las transformaciones del peronismo. Bs. As.: Losada.

Palermo, Vicente (1999). ¿Mejorar para empeorar? La dinámica política de las reformas estructurales argentinas. En M. Novaro (Comp.). Entre el abismo y la ilusión. Peronismo, democracia y mercado (pp. 37-88). Bs. As.: Norma.

Palermo, Vicente y Novaro, Marcos (1996). Política y poder en el gobierno de Menem, Bs. As.: Norma-FLACSO.

Repetto, Fabián (1999). Transformaciones de la política social y su relación con la legitimidad: notas sobre América Latina en los '90, Postdata, 5, noviembre, 147-171.

Rinesi, Eduardo y Vommaro, Gabriel (2007). Notas sobre la democracia, sobre la representación y algunos problemas conexos. En E. Rinesi, G. Nardacchione y G. Vommaro (comps.). Los lentes de Victor Hugo. Transformaciones políticas y desafíos teóricos en la Argentina reciente. Bs. As. Prometeo-UNGS (pp. 419-472).

Sigal, Silvia y Verón, Eliseo (2003). Perón o muerte. Los fundamentos discursivos del fenómeno peronista. Bs. As.: Legasa.

Verón, Eliseo (1995). Semiosis de lo ideológico y el poder. Bs. As.: UBA. 
Volóshinov, Valentín (1992). El marxismo y la filosofía del lenguaje, Madrid: Alianza Universidad.

\section{Fuentes y documentos}

\section{Diario Clarín}

Diario La Nación

Diario Página 12

Anexos del discurso presidencial de apertura del 113 período de sesiones ordinarias del Congreso Nacional, 1 de marzo de 1995, Presidencia de la Nación, República Argentina.

Ministerio de Economía y Obras y Servicios Públicos (2004): "Crecimiento y distribución del ingreso por provincias 1991-1996", MEyOSP, Bs. As., noviembre.

Sistema integrado y Analítico de información sobre reforma del Estado, gestión y políticas públicas (SIARE). URL: http://www.clad.org.ve/siare/tamano/estadistica.html

Discursos oficiales del presidente de la Nación, Dr. Carlos Saúl Menem, Dirección General de Difusión, Secretaría de Medios de Comunicación, Presidencia de la Nación, República Argentina (varios tomos). 